\title{
Effect of Generating Heat on Ozone Generation in Dielectric Cylinder-Cylinder DBD Ozone Generator
}

\author{
Surapon Boonduang ${ }^{*}$ Pichet Limsuwan \\ Department of Physics, Faculty of Science, King Mongkut's University of Technology, Bangkok, Thailand \\ Email: *opticslaser@yahoo.com
}

Received September 16, 2013; revised October 16, 2013; accepted October 23, 2013

Copyright (c) 2013 Surapon Boonduang, Pichet Limsuwan. This is an open access article distributed under the Creative Commons Attribution License, which permits unrestricted use, distribution, and reproduction in any medium, provided the original work is properly cited.

\begin{abstract}
A cylinder-cylinder dielectric-barrier discharge (DBD) ozone generator has been developed. The ozone concentration was measured at an oxygen pressure of $1.02 \mathrm{~atm}$ and an oxygen flow rate of $12 \mathrm{~L} / \mathrm{min}$. The heat generated in the ozone tube during the operation of the ozone generator was investigated using a thermal camera. The infrared (IR) images and corresponding temperatures of the ozone tube surfaces at different operating times were observed. The IR images showed the generating of the inhomogeneous heat-up along the ozone tube surface which results in the decrease of the ozone production efficiency.
\end{abstract}

Keywords: Cylinder-Cylinder DBD; Ozone Generator; Ozone Concentration; Thermal Camera

\section{Introduction}

Nowadays, ozone has attracted attention in the environmental improvement technology, when the environmental problem has become a topic on a world scale. Since ozone is one of the strongest oxidants, it is widely used for treatment of wasted water and offensives odors, disinfections and the removal of organic substances [1]. Ozone is widely used in industrial and domestic applications. It is also widely used in food processing, food storage, odor abatement, groundwater remediation and drinking water purification [2-4].

In current industrial ozone generators, the DBD discharge configuration is usually employed. In this arrangement, dried air or oxygen flows through a discharge gap of 1 - $2 \mathrm{~mm}$ width. One side of the gap is formed by a metal electrode at ground potential and the other one by a dielectric, normally glass or ceramic, in good contact with a high voltage electrode. An alternating voltage is applied across the two electrodes so that the resulting alternating electric field is high enough to raise electrical breakdown. Since ozone generators operate at pressures of a few bars, the peak voltage of several kilovolts is needed to initiate the discharge [5].

Recently, DBD is the most extensively studied for ozone generation. It is known that DBD generates a non-

\footnotetext{
"Corresponding author.
}

thermal equilibrium plasma even under atmospheric pressure, which is suitable for ozone production [6-9]. However, some ozone generator configurations generate inhomogeneous heat-up of the dielectric barrier and result in the decrease of ozone production efficiency. Experimental studies concerning ozone generator configuration such as electrode arrangements, gap lengths, dielectric materials, operating gases and electrical discharges have been widely studied to obtain the optimum discharge conditions for high yield ozone production [8-17].

In this work, a cylinder-cylinder DBD ozone generator has been developed. The heat generated in the ozone tube was investigated using a thermal camera and reported as IR images and temperature values. The ozone concentration as a function of operating time of ozone tube was also measured. The relation between the ozone concentration and temperature was reported.

\section{Experimental Arrangements}

\subsection{Experimental Setup}

Figure 1 shows the schematic diagram of the experimental setup. A commercial grade oxygen from oxygen tank with a purity of $95 \%$ was used for ozone production. It was filtered and controlled by a pressure regulator to release oxygen at a constant pressure of $4.0 \mathrm{~atm}$. Then, it passed through the mass flow controller which controlled 


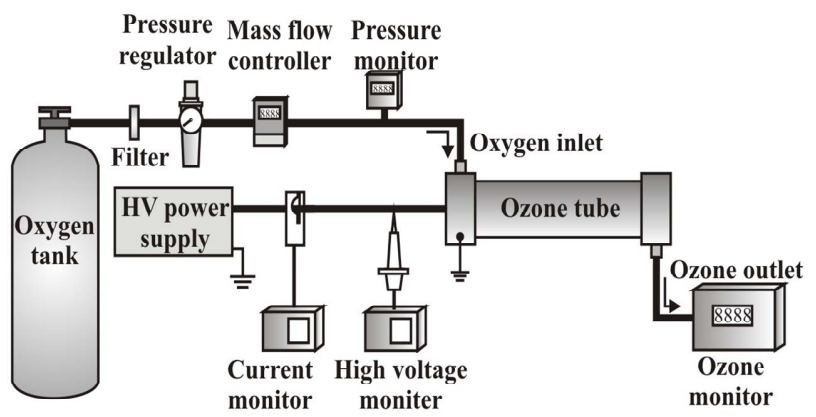

Figure 1. Schematic diagram of the experimental setup for ozone generation.

the oxygen flow rate. The selected pressure and flow rate of oxygen finally passed into the ozone tube. Oxygen in the ozone tube was discharged by a high voltage power supply and ozone was released to the ozone monitor. In this work, the oxygen flow rate and oxygen pressure were kept constant at $12 \mathrm{~L} / \mathrm{min}$ and $1.02 \mathrm{~atm}$., respectively.

\subsection{Ozone Tube}

Figure 2 shows the configurations of the ozone tube. It consisted of a stainless steel sheath with an outer diameter of $40 \mathrm{~mm}$ and $24 \mathrm{~cm}$ long. It was inserted in a glass tube with a tight contact of their surfaces. The glass tube with a thickness of $1.7 \mathrm{~mm}, 30 \mathrm{~cm}$ long and $42 \mathrm{~mm}$ outer diameter was used as a dielectric barrier. The grounded cylindrical electrode was a stainless steel tube with an inner diameter of $43 \mathrm{~mm}$ and $25 \mathrm{~cm}$ long. Therefore, the air gap and active length of the ozone tube to produce ozone were $0.5 \mathrm{~mm}$ and $24 \mathrm{~cm}$, respectively.

\subsection{High Voltage Power Supply}

The high voltage power supply used in this study is of a switching type. Figure 3 shows the schematic diagram of the high voltage switching power supply. A $220 \mathrm{~V}$ ac voltage was stepped down by a transformer and rectified by a rectifier into dc voltage of about $72 \mathrm{~V}$. IGBT (Insulated Gate Bipolar Transistor) was used as electronic switch and controlled by an oscillator to generate a high frequency current in the range of $0-4 \mathrm{~A}_{\mathrm{rms}}\left(0-24 \mathrm{~A}_{\mathrm{p}-\mathrm{p}}\right)$. Low voltage with high frequency current was stepped up by a high voltage step up transformer, and then the voltage of $1-10 \mathrm{kV}$ at frequency of $0-10 \mathrm{kHz}$ was obtained. In present work, the optimum frequency to discharge oxygen in the ozone tube was $3.7 \mathrm{kHz}$.

\subsection{Electrical Measurements}

The voltage and current were measured using a high voltage probe (Fluke 80K-6) and a current probe (Fluke 40i-1105), respectively. Waveforms were recorded using a digital storage oscilloscope (Agilent 54621A).

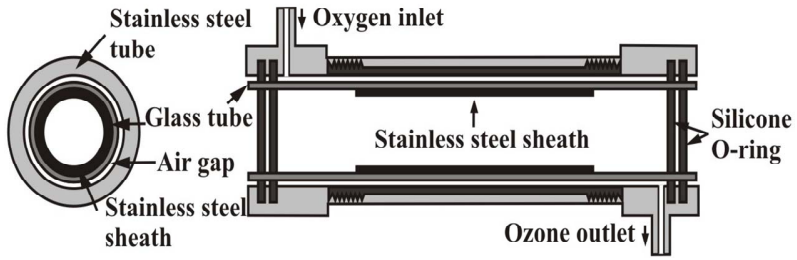

Figure 2. Configurations of the ozone tube.

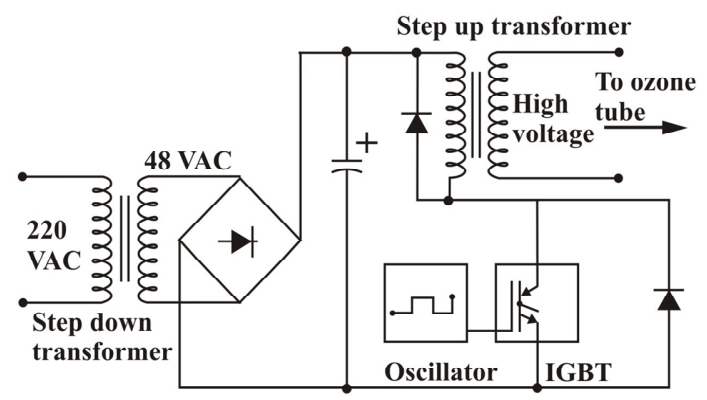

Figure 3. High voltage power supply.

\subsection{Ozone Concentration Measurements}

The ozone released from the ozone tube as shown in the experimental setup (Figure 1) was measured using an ozone monitor (Quant Ozone "2"). The measurements were carried out at an oxygen pressure of $1.02 \mathrm{~atm}$ and an oxygen flow rate of $12 \mathrm{~L} / \mathrm{min}$.

\subsection{Temperature Measurements}

The heat generated in the ozone tube was investigated using a thermal camera (Infra Tech, model Image IR 3300U). The IR images corresponding to the generated heat were obtained. In addition, the temperature of the ozone tube surface at different areas was also obtained from IR camera. The IR images of the ozone tube at 5 positions as shown in Figure $\mathbf{4}$ were recorded simultaneously, and then the corresponding surface temperatures were displayed. The operating time of the ozone tube for IR imaging was $10 \mathrm{~min}$.

\section{Results and Discussion}

The typical waveforms of the discharge voltage, current and power at an oxygen pressure of $1.02 \mathrm{~atm}$ and an oxygen flow rate of $12 \mathrm{~L} / \mathrm{min}$ are shown in Figures 5 (a)-(c), respectively.

The variations of the ozone concentration, voltage and current as a function of the operating time of the ozone tube are shown in Figures 6(a)-(c), respectively.

As seen in Figure 6(a), it is clearly observed that the ozone concentration decreases rapidly with increasing operating time of the ozone tube. The ozone concentration decreased from about $14 \mathrm{~g} / \mathrm{h}$ at the beginning to 3 $\mathrm{g} / \mathrm{h}$ after the ozone generator operates for $10 \mathrm{~min}$. How 


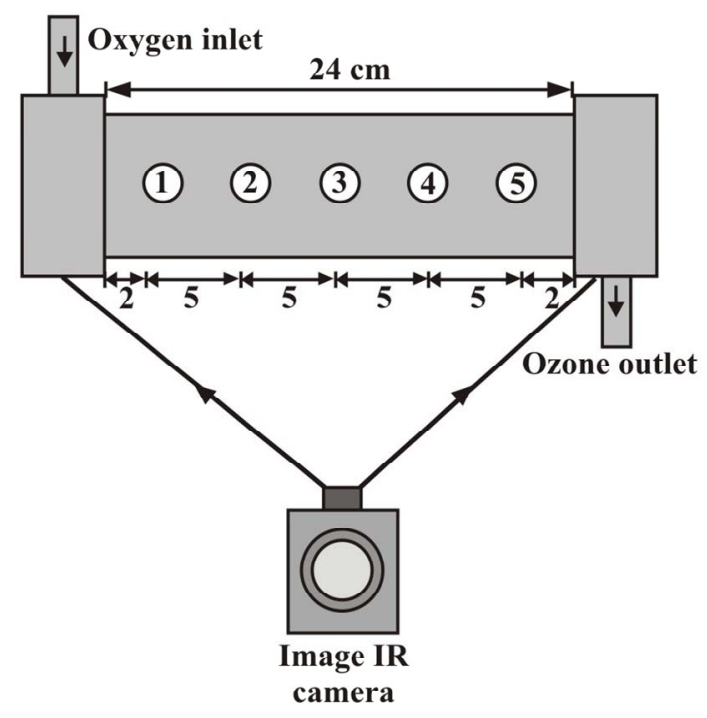

Figure 4. Schematic diagram for IR imaging.
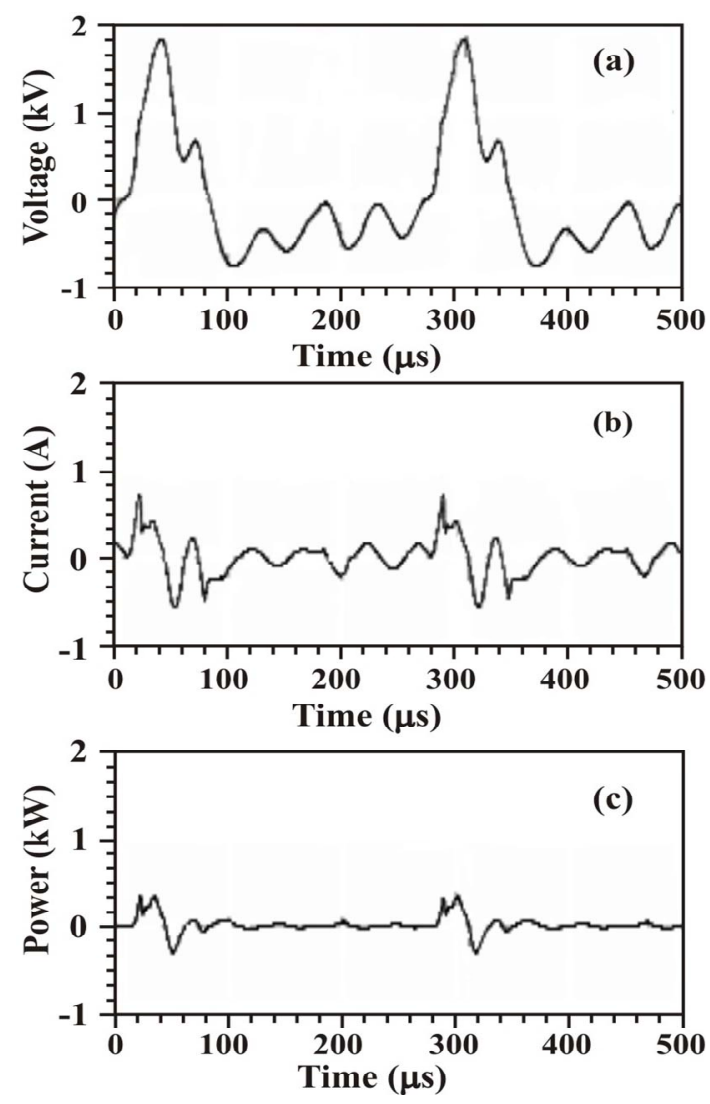

Figure 5. Waveforms of: (a) discharge voltage, (b) current and (c) power.

ever, the voltage and current are considerably constant through the whole range of operating time.

Figure 7 shows the IR images of the ozone tube surface from the beginning to the 10th $\mathrm{min}$. The temperatures at the positions $1,2,3,4$ and 5 on the ozone tube surface were recorded simultaneously. The surface tem- peratures of the positions $1,2,3,4$ and 5 as a function of the operating time are shown in Figure 8.

It is seen that the temperature at all positions on the ozone tube surface increases with the increase of operating time. Furthermore, the temperatures at different positions are significantly different. At the position close to the oxygen inlet such as position 1, the temperature is much lower than that of the one that far from the oxygen inlet such as position 5. The maximum temperature change with operating time is observed at the position 5 . The temperature is found to increase from room temperature $\left(26.0^{\circ} \mathrm{C}\right)$ to $97.0^{\circ} \mathrm{C}$ after operating of the ozone tube for $10 \mathrm{~min}$. The increase of the temperature of the ozone tube results in the decrease of the ozone concentration as confirmed by Figure 6(a).

The present work has shown that the heat is generated rapidly in the ozone tube. In addition, the heat generated at different positions along the ozone tube is much dif ferent. The generating of the inhomogeneous heat-up
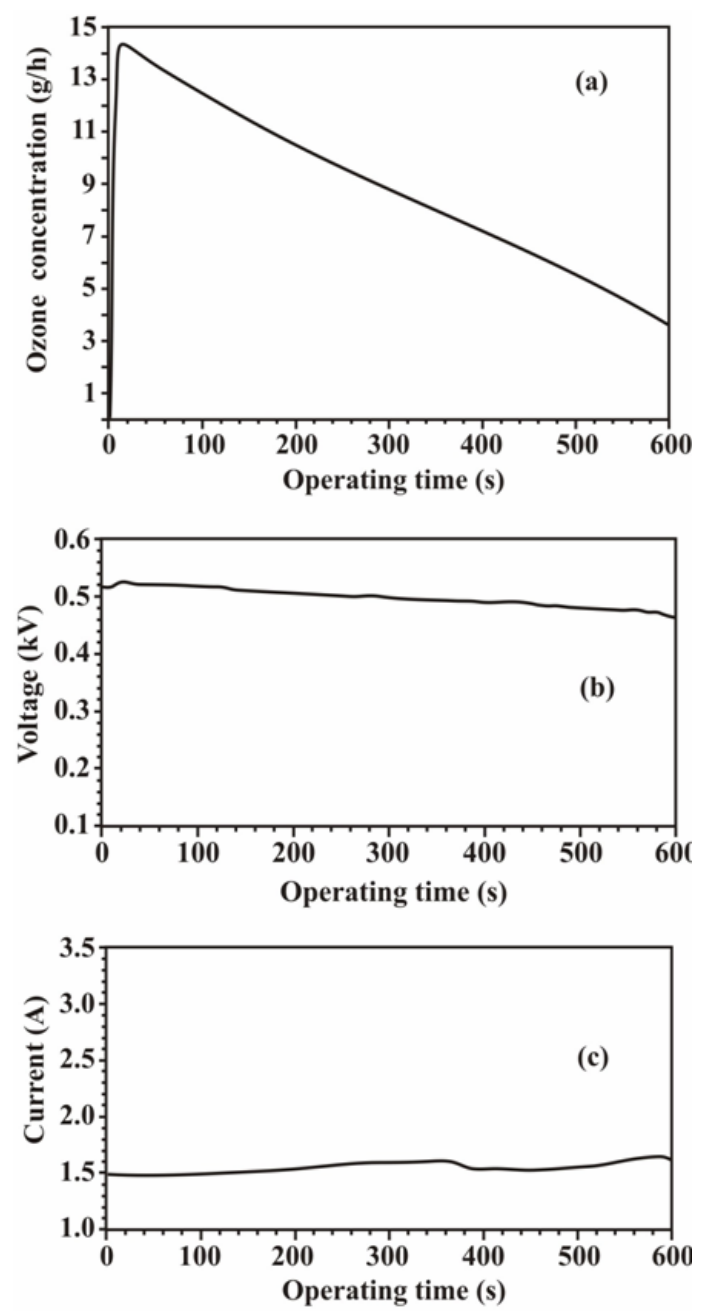

Figure 6. Variations of: (a) ozone concentration, (b) rms voltage and (c) rms current as a function of the operating time. 

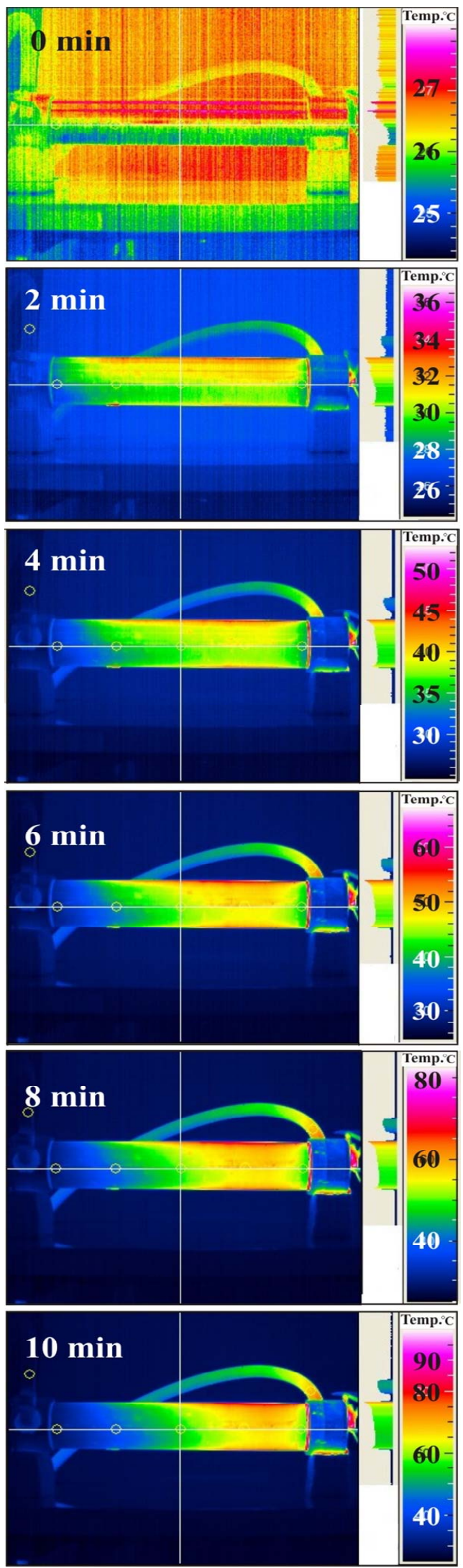

Figure 7. IR images of the ozone tube surface at different operating times.

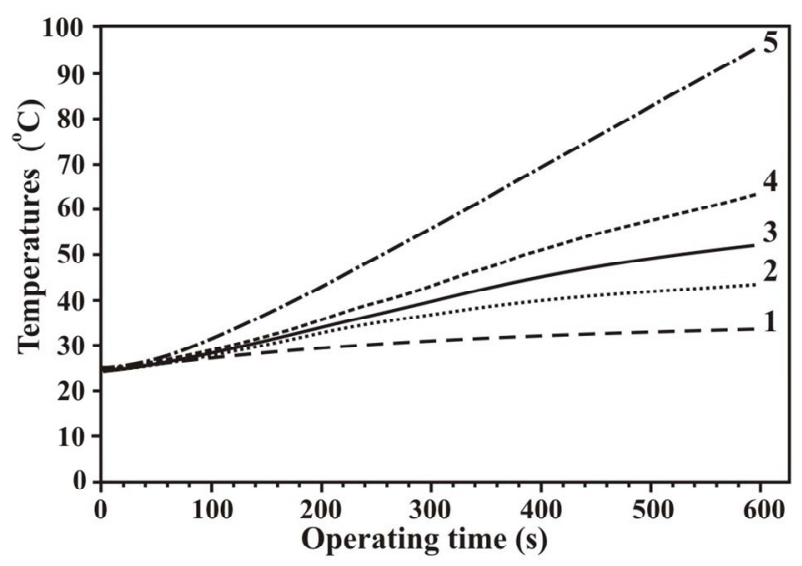

Figure 8. Variations of the surface temperature at different positions on the ozone tube as a function of the operating time.

results in the decrease of ozone production efficiency. Therefore, the heat generated in the ozone tube has much effect on the production of ozone in the ozone generator. We can improve the efficiency of the ozone production system by reducing the heat from the ozone tube surface. One method can be made by covering the grounded cylindrical electrode (outer stainless steel tube) with a heat dissipator. For example, two half-cylindrical aluminum tubes with longitudinal fins can be used to cover the grounded stainless electrode, which behave as a heat dissipater. This work will be left for further development.

\section{Conclusion}

In this work, a cylinder-cylinder DBD ozone generator has been developed. The ozone concentration measurements and the investigation of heat generated on the ozone tube surface were carried out at an oxygen pressure of $1.02 \mathrm{~atm}$ and an oxygen flow rate of $12 \mathrm{~L} / \mathrm{min}$. It was found that the heat generated in the ozone tube during the operation of the ozone generator significantly reduced the ozone production efficiency.

\section{Acknowledgements}

This work had partially been supported by Thailand Center of Excellence in Physics (ThEP) and King Mongkut's University of Technology Thonburi under The National Research University Project.

\section{REFERENCES}

[1] U. Kogelschatz, “Advanced Ozone Generator,” Plenum Press, New York, 1998, p. 87.

[2] B. L. Loeb, "Ozone: Science \& Engineering: ThirtyThree Years and Growing,” Ozone: Science \& Engineering, Vol. 33, 2011, pp. 329-342. http://dx.doi.org/10.1080/01919512.2011.584302 
[3] R. G. Rice, "Ozone in the United States of America-State of the Art,” Ozone: Science \& Engineering, Vol. 21, 1999, pp. 99-118. http://dx.doi.org/10.1080/01919519908547244

[4] A. Böhme, "Ozone Technology of German Industrial Enterprises,” Ozone: Science \& Engineering, Vol. 21, 1999, pp. 163-176. http://dx.doi.org/10.1080/01919519908547250

[5] U. Kogelschatz and B. Eliasson, "Handbook of Electrostatic Process,” Marcel Dekker, New York, 1995.

[6] X. Xu, "Dielectric Barrier Discharge-Properties and Applications,” Thin Solid Films, Vol. 390, No. 1-2, 2001, pp. 237-242. http://dx.doi.org/10.1016/S0040-6090(01)00956-7

[7] M. Moreau, N. Orange and M. G. J. Feuilloley, "NonThermal Plasma Technologies: New Tools for Bio-Decontamination,” Biotechnology Advances, Vol. 26, No. 6, 2008, pp. 610-617. http://dx.doi.org/10.1016/j.biotechadv.2008.08.001

[8] K. Takaki, Y. Hatanaka, K. Arima, S. Mukaigawa and T. Fujiwara, "Influence of Electrode Configuration on Ozone Synthesis and Microdischarge Property in Dielectric Barrier Discharge Reactor,” Vacuum, Vol. 83, No. 1, 2009, pp. 128-132. http://dx.doi.org/10.1016/j.vacuum.2008.03.047

[9] Z. Fang, Y. Qiu, Y. Sun, H. Wang and K. Edmund, “Experimental Study on Discharge Characteristics and Ozone Generation of Dielectric Barrier Discharge in A Cylinder-Cylinder Reactor and a Wire-Cylinder Reactor,” Journal Electrostatics, Vol. 66, No. 7-8, 2008, pp. 421-426. http://dx.doi.org/10.1016/j.elstat.2008.04.007

[10] S. L. Park, J. D. Moon, S. H. Lee and S. Y. Shin, "Effective Ozone Generation Utilizing a Meshed-Plate Electrode in A Dielectric-Barrier Discharge Type Ozone Generator,” Journal Electrostatics, Vol. 64, No. 5, 2006, pp. 275-282. http://dx.doi.org/10.1016/j.elstat.2005.06.007

[11] M. Takayama, K. Ebihara, H. Stryczewska, T. Ikegami, Y. Gyoutoku, K. Kubo and M. Tachibana, "Ozone Generation by Dielectric Barrier Discharge for Soil Sterilization,” Thin Solid Films, Vol. 506-507, 2006, pp. 396-399. http://dx.doi.org/10.1016/j.tsf.2005.08.332

[12] J. D. Moon and J. S. Jung, "Effective Corona Discharge and Ozone Generation from a Wire-Plate Discharge System with a Slit Dielectric Barrier,” Journal Electrostatics, Vol. 65, No. 10-11, 2007, pp. 660-666. http://dx.doi.org/10.1016/j.elstat.2007.05.001

[13] I. Jenei and E. Kiss, "Development of the Ozone Generation by the Variation of Auxiliary Electrodes," Journal Electrostatics, Vol. 63, No. 6-10, 2005, pp. 985-991. http://dx.doi.org/10.1016/j.elstat.2005.03.072

[14] S. Kaneda, N. Hayashi, S. Ihara, S. Satoh and C. Yamabe "Application of Dielectric Material to Double-Discharge-Type Ozonizer,” Vacuum, Vol. 73, No. 3-4, 2004, pp. 567-571.

http://dx.doi.org/10.1016/j.vacuum.2003.12.088

[15] M. Shimosaki, N. Hayashi, S. Ihara, S. Satoh and C. Yamabe, "Effect of Trigger Electrodes Configuration of A Double Discharge Ozonizer on Ozone Generation Characteristics,” Vacuum, Vol. 73, No. 3-4, 2004, pp. 573-577. http://dx.doi.org/10.1016/j.vacuum.2003.12.089

[16] Y. M. Sung and T. Sakoda, “Optimum Conditions for Ozone Formation in a Micro Dielectric Barrier Discharge," Surface and Coatings Technology, Vol. 197, No. 2-3, 2005, pp. 148-153. http://dx.doi.org/10.1016/j.surfcoat.2004.09.031

[17] J. S. Jung and J. D. Moon, “Corona Discharge and Ozone Generation Characteristics of a Wire-Plate Discharge System with A Glass-Fiber Layer," Journal Electrostatics, Vol. 66, No. 5-6, 2008, pp. 335-341. http://dx.doi.org/10.1016/j.elstat.2008.02.003 